\title{
"EU GANHEI MAIS O GOSTO DE ESTUDAR": O E-LEARNING COMO UM MEIO DE APRENDIZAGEM AO LONGO DA VIDA DE RECLUSAS DE UM ESTABELECIMENTO PRISIONAL PORTUGUÊS*
}

\author{
Angélica Monteiro ${ }^{1}$ \\ CARLinda Leite ${ }^{1}$ \\ Rita BARRos ${ }^{2}$
}

\begin{abstract}
RESUMO: $\mathrm{O}$ artigo estudou as percepções de reclusas sobre formação na modalidade e-learning, num estabelecimento prisional feminino de Portugal. A análise do curso e da formação, inscritos no paradigma de aprendizagem ao longo da vida, objetiva estudar a possibilidade do e-learning constituir um dispositivo de diferenciação pedagógica que promove a inclusão digital. Os dados relativos ao percurso de aprendizagem em regime de e-learning foram recolhidos por dois questionários e um grupo focal. A análise dos dados evidencia que essas formandas, reclusas, consideram que a experiência de formação em e-learning lhes devolveu a confiança de que ainda têm capacidade de realizar novas aprendizagens, com impacto em perspectivas relacionadas a uma futura inserção no mercado de trabalho.
\end{abstract}

Palavras-chave: Aprendizagem ao longo da vida. Inclusão digital. E-learning. Educação prisional.

\section{"I HAVE STARTED TO ENJOY STUDYING": E-LEARNING AS A MEAN OF INMATES' LIFELONG LEARNING IN A PORTUGUESE PRISON}

ABSTRACT: The article analysed inmates' perceptions on e-learning training, in a female prison in Portugal. The course analysis and training focus is supported in the lifelong learning paradigm and its objective is to study the possibility of e-learning as a pedagogical differentiation

\footnotetext{
*Artigo derivado do projeto estratégico do Centro de Investigaçáo e Intervençấo Educativas da Faculdade de Psicologia e de Ciências da Educação, Universidade do Porto, e do Research in Education and Community Intervention, com a referência SFRH/BPD/92427/2013, financiado parcialmente por Fundos Nacionais pela Fundaçáo para a Ciência e a Tecnologia, Portugal.

${ }^{1}$ Centro de Investigação e Intervenção Educativas, Faculdade de Psicologia e de Ciências da Educação, Universidade do Porto - Porto, Portugal. E-mails: armonteiro@fpce.up.pt, carlinda@fpce.up.pt

${ }^{2}$ Research in Education and Community Intervention, Instituto Piaget - Vila Nova de Gaia, Portugal. E-mail: rita.barros@gaia.ipiaget.pt DOI: 10.1590/ES0101-7330216156650
} 
dispositive that promotes digital inclusion. Data about the lifelong learning course, using e-learning and learning skills, were gathered by means of two questionnaires and a focus group. The analysis shows that these trainers, in a prison situation, recognize that the experience of e-learning training gave them confidence and proved to them that they still have the ability of undertaking new apprenticeships, with an impact on perspectives related to future integration into the labour market.

Keywords: Lilelong learning. Digital inclusion. E-learning. Prisional education.

\section{«JE DEVELOPPE LE PLAISIR D'ETUDIER»: E-LEARNING COMME UN MOYEN DE L'APPRENTISSAGE A VIE DES DETENUS DANS UNE PRISON PORTUGAISE}

RÉSUMÉ: Cet article analyse les perceptions des détenues par rapport à une formation conçue selon dans la modalité de e-learning et qui s'est déroulé dans un établissement carcéral féminin au Portugal. L'analyse de ce cours de formation, qui s'inscrit dans le paradigme d'apprentissage tout au long de la vie, avait pour objectif d'étudier les possibilités de e-learning à construire un dispositif de différentiation pédagogique promoteur de l'inclusion numérique. Les données, relatives au parcours d'apprentissage en régime e-learning ont été recueillies par deux questionnaires et un focus group. L'analyse des données a mis en évidence que les détenues considèrent cet expérience de formation e-learning les a rassurés quant à leur capacité d'effectuer de nouveaux apprentissages et l'impact que ceci peut avoir sur leur insertion future dans le marché du travail.

Mots-clés: L'apprentissage lilelong. L'inclusion numérique. L'e-learning. L'éducation en prison.

\section{Introdução}

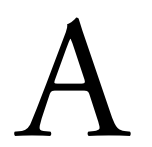

garantia de acesso universal à educação e o reconhecimento da necessidade de desenvolver uma sociedade inclusiva, na qual todos possam criar, aceder, utilizar e compartilhar informaçóes e conhecimento, estão patentes, segundo a Organização das Naçóes Unidas para a Educação, a Ciência e a Cultura (UNESCO, 2012), nas principais declaraçóes internacionais. Delas são exemplo a Declaração Universal dos Direitos Humanos (art. 26.1); a Declaração do Milênio e Plano de Açáo de Dacar, de 2000; a Declaração de Princípios da Cimeira Mundial sobre a Sociedade da Informação, de 2003; e as declarações das seis Conferências Internacionais sobre a Educação de Adultos (CONFITEA), que salientam o papel fundamental da educação de adultos para o desenvolvimento da sociedade. 
No mesmo sentido, a União Europeia (UE) tem desenvolvido estratégias, como a "Estratégia de Lisboa" (COMISSÁO DAS COMUNIDADES EUROPEIAS, 2000) e a "Estratégia Europa 2020" (COMISSÃO EUROPEIA, 2010), as quais têm como objetivo preparar a economia europeia para a próxima década, numa lógica de crescimento inteligente, sustentável e inclusivo. Uma análise desses discursos internacionais permite constatar que as medidas propostas reconhecem a educação e a formação como meios de adaptaçáo às demandas da sociedade do conhecimento e ao modelo europeu de coesão social. Exemplo disso é o reconhecimento, pela Comissão Europeia, da necessidade de que "todos os cidadãos possuam as qualificaçóes necessárias para viver e trabalhar na nova sociedade da informação" (COMISSÃO DAS COMUNIDADES EUROPEIAS, 2000, p. 13), o que exige, necessariamente, uma atenção particular às minorias e às populaçôes em risco ou em situação de exclusões digital e social. Foi tendo por referência essa ideia que foi desenvolvida a formaçáo em e-learning a que se refere este artigo.

Corroboramos a ideia de que educação em contexto prisional, para além de um direito fundamental, pode constituir um meio de colmatar as lacunas na aprendizagem e competências das pessoas adultas, de melhorar a sua empregabilidade e mudar suas atitudes e percepçóes pessoais (HAWLEY; MURPHY; SOUTO-OTERO, 2013). Consideramos ainda nesse campo intervir, uma vez que a população em situação de reclusão na Europa apresenta, em média ${ }^{1}$, um baixo nível de desenvolvimento de competências básicas (literacia, numeracia e linguagem) e enfrenta uma série de barreiras à participação em atividades de aprendizagem ao longo da vida - ALV (RANGEL, 2007). Especificamente em Portugal, apesar de sucessivas reformulaçóes no discurso político no âmbito da educação de adultos, ainda se encontra uma população "adulta com percursos escolares curtos, muitos destes marcados pelo absentismo, insucesso e abandono escolar" (GUIMARÁES; BARROS, 2015, p. 402).

Orienta-nos a crença de que algumas das limitaçóes para a ALV podem ser minimizadas, ou até mesmo ultrapassadas, por meio da diversificação dos meios de ensino, do estímulo à participação ativa dos(as) aprendentes adultos(as) e do envolvimento desses em projetos que impliquem uma análise crítica da própria situaçáo de vida, no que se refere ao percurso formativo. Como ponto de partida, admitimos que o e-learning poderia impulsionar uma mudança de postura frente às oportunidades de aprendizagem. Nessa mesma linha, a legislação portuguesa reconhece o e-learning como um contributo fundamental para a promoção da ALV (PORTUGAL, 2005). Apostopoulou et al. (2004) apresentam-no como um meio para expandir as competências de literacia digital e para uma autoformação que vise uma melhor qualidade de vida.

É tendo por referência essas ideias que o presente trabalho discutiu as potencialidades do e-learning como dispositivo de diferenciação pedagógica (CORTESÁO; STOER, 1999) que promove a inclusão digital. Para isso, reali- 
zou-se um estudo que recolheu percepçóes de dez reclusas de um estabelecimento prisional (EP) do Norte de Portugal, participantes no projeto "E-learning em estabelecimentos prisionais” (EPRIS) (BARROS; MONTEIRO, 2015). Esse é um projeto-piloto, enquadrado num protocolo de colaboração entre o Ministério da Justiça português, uma instituição de solidariedade social e uma instituição de ensino superior, que visa contribuir para a reinserção social da população reclusa, criando modelos de intervenção integrada e estruturada, suscetível de replicação/ disseminação, com o recurso às tecnologias de informação e comunicação (TIC) enquanto instrumento de inclusão digital e social.

Em sua estrutura, o artigo apresenta um breve enquadramento acerca do e-learning como meio promotor de inclusão digital e da situação no contexto prisional da Europa. São ainda mostrados os aspetos metodológicos que sustentaram a recolha de dados e a posterior análise das percepçóes das formandas/reclusas sobre o percurso em ALV e a formação em e-learning e sobre as suas competências de autoaprendizagem.

\section{O e-learning como dispositivo de diferenciação pedagógica, potenciador de inclusão digital}

A definição de e-learning é influenciada por diversas variáveis e múltiplos fatores que se entrecruzam e se influenciam (MONTEIRO; BARROS; LEITE, 2015). Neste texto, o conceito de e-learning refere-se ao processo de mediação on-line de aprendizagens, que pressupóe o desenvolvimento de competências pessoais, cognitivas e sociais, a partir da interação num ambiente virtual de aprendizagem cuidadosamente planejado e dinamizado, com base nos modelos pedagógicos que os sustentam, e tem como finalidade a autoformação dos sujeitos envolvidos, ou seja, nas palavras de Valle e Bohadana (2012, p. 982), trata-se de uma "práxis constante, que implica necessariamente a presença do outro, que é constantemente atual, a começar e a recomeçar, num movimento incessante que se chama: vida”.

Como foi referido noutra altura (MONTEIRO; BARROS; LEITE, 2015), dada a variedade das soluçóes de e-learning, há a possibilidade de que os adultos tenham acesso à Internet e à formação por e-learning sem condições adequadas para uma participação sustentada, em que as características pessoais e culturais de quem a utiliza, bem como as do contexto de aprendizagem, não são reconhecidos, nem respeitadas. Essa situação pode favorecer a exclusão digital. De fato, a participação em ambientes on-line requer práticas colaborativas e que tenham no seu foco especificidades do(a) aprendiz. A esse respeito, é importante considerar aspectos relacionados com a pessoa que está aprendendo e com os processos de formação. O Quadro 1 sistematiza alguns desses aspectos.

Assumimos, como princípio de formação, que quando nas etapas do desenvolvimento do ambiente digital de aprendizagem são considerados os aspectos 
relativos aos(às) aprendentes adultos(as) referidos no Quadro 1, o e-learning pode configurar-se como um dispositivo de diferenciação pedagógica. Reconhecemos, tal como Cortesão (2012, p. 728), a importância desse conceito

concebido e utilizado num determinado contexto educativo e sociocultural, para e com um determinado tipo de aluno, considerando problemas e/ou interesses e saberes que, se descobre, assumem, para eles, particular relevância.

Reconhecemos, ainda, que os ambientes digitais de aprendizagem podem facilitar a diversificação dos recursos de ensino, bem como a sua partilha por um discurso pedagógico que respeita e valoriza a multiculturalidade, contribuindo, portanto, para reduzir a lacuna digital, no que diz respeito ao acesso e à participação dos adultos. No entanto, o processo de participação que se estabelece na "relação pedagógica que tira partido da natureza mestiça e poliglota do campo de saber em que trabalha” (CORTESÃO, 2012, p. 723), exige do(a) responsável pela formação mais do que uma simples "tradução" de conteúdos, ou seja, uma produção de conhecimentos alicerçada na investigação-ação da sua prática pedagógica, sendo essa a principal particularidade de um dispositivo de diferenciaçáo pedagógica. Essa ideia assemelha-se ao conceito de ambientes digitais abertos e flexíveis referidos por Ngeow e Kong $(2002$, p. 2)르 , que têm como características:

- $\quad$ refletem as múltiplas e diversas realidades culturais das minorias e da sociedade dominante de massa;

- incluem várias formas culturais de conhecer, interagir, aprender e ensinar;

- promovem a aceitaçáo e a equidade dos diversos resultados de aprendizagem”.

\section{Quadro 1}

Aspectos para considerar na formação de adultos em e-learning.

\begin{tabular}{|c|c|}
\hline Dimensão & Aspectos \\
\hline Adultos & $\begin{array}{l}\text { Contextos da vida (trabalho, família, social). } \\
\text { Características pessoais (idade, sexo, situação económica e cultural). } \\
\text { Aprendizagem (necessidades, estilos, background, preocupaçóes, } \\
\text { conhecimento prévio, competências, literacia digital). } \\
\text { Atitudes, motivação e compromisso com a aprendizagem. }\end{array}$ \\
\hline $\begin{array}{l}\text { E-learning para a } \\
\text { aprendizagem ao } \\
\text { longo da vida }\end{array}$ & $\begin{array}{c}\text { Variáveis tecnológicas (conexão, acesso, suporte, disponibilidade, } \\
\text { meio de comunicação). } \\
\text { Aspetos institucionais (gestão, organização, formação de pessoal, motivação). } \\
\text { Variáveis pedagógicas (papéis, atividades formativas, estratégias de ensino, } \\
\text { abordagens, desenvolvimento curricular, métodos de avaliação, conteúdos, } \\
\text { ambiente virtual de aprendizagem, linguagem, nível de interação). } \\
\text { Confiança (conceito de e-Learning, natureza, segurança, privacidade, } \\
\text { credibilidade, relevância). }\end{array}$ \\
\hline
\end{tabular}




\section{O e-learning em contexto prisional na Europa}

$\mathrm{Na}$ Europa, foram desenvolvidos alguns projetos de e-learning em contexto prisional, financiados por programas europeus de ALV, enquadrados em subprogramas, tais como o Grundtvig (educação de adultos) e o Leonardo da Vinci (ensino vocacional). Como exemplos desses projetos é de salientar: o Partnership in Prison Education Learning in Networked Environments (PIPELINE) (Noruega, República Checa, Dinamarca, Alemanha, Romênia, Slovenia, Suécia, Reino Unido) e o Learning Infrastructure for Correctional Services - European Transfer (LICOS) (Alemanha, Noruega, Áustria, Espanha, Holanda e Hungria).

O projeto PIPELINE (2005-2007), de acordo com o documento Grundtvig and Leonardo da Vinci catalogue of projects on prison education \& training (GHK, 2010), tinha como objetivo a melhoria da educação. Os principais resultados desse projeto foram:

- $\quad$ o desenvolvimento de um sistema de segurança que pode ser adaptado às diferentes necessidades organizacionais e pedagógicas e às demandas de ambientes de aprendizagem de diferentes EPs;

- o desenvolvimento de uma plataforma de e-learning, um sistema de publicação de exemplos de práticas de multiliteracias;

- o aumento do sentimento de autoestima.

Por sua vez, o projeto LICOS (2008-2010) tinha por objetivo "construir um framework para a implementação de sistemas de e-learning na educação em contexto prisional" (LICOS, 2010).

Os princípios do modelo pedagógico desenvolvido por esse projeto basearam-se nos conceitos de construtivismo, aprendizagem colaborativa, incentivo à motivação e estímulo à curiosidade. Quanto às recomendações feitas pelo projeto LICOS, elas foram organizadas em seis grandes temas: educaçáo prisional; e-learning como um recurso estratégico de qualificação em serviços correcionais; processo de introdução ao e-learning; contexto de aprendizagem; utilização segura de recursos da Internet e incorporação do e-learning numa estratégia mais ampla de qualificação (LICOS, 2010). O Quadro 2 apresenta, resumidamente, as principais recomendaçóes acerca de cada um desses temas.

Das recomendaçóes resultantes desse projeto europeu, no curso de formação a que se refere este artigo, no âmbito do projeto EPRIS e que, repete-se, foi desenvolvido num EP no Norte de Portugal, foram tidos principalmente em consideração: o modo de introdução do curso para que as reclusas se sentissem envolvidas; assegurar a existência de apoios no interior do EP; criação de um ambiente seguro de acesso à Internet; atenção às etapas de formação, para não descurar processos que 


\section{Quadro 2}

E-learning em educaçáo prisional na Europa recomendaçóes para decisores políticos europeus.

\begin{tabular}{|c|c|}
\hline Temas & Recomendaçóes \\
\hline \multirow[b]{2}{*}{$\begin{array}{l}\text { Educação em } \\
\text { contexto prisional }\end{array}$} & $\begin{array}{l}\text { A reintegraçáo social dos transgressores é um dos objetivos levados em } \\
\text { consideracáo no estabelecimento da sentença criminal. }\end{array}$ \\
\hline & $\begin{array}{l}\text { A educaçáo e a formação nas prisóes devem ter níveis de competência } \\
\text { comparáveis com os que são oferecidos no exterior. O e-learning } \\
\text { pode auxiliar a concretizaçáo desse objetivo pelo acesso a recursos de } \\
\text { aprendizagem de outras instituiçôes de ensino. }\end{array}$ \\
\hline \multirow{3}{*}{$\begin{array}{l}\text { E-learning para } \\
\text { a qualificação } \\
\text { em serviços } \\
\text { correcionais }\end{array}$} & $\begin{array}{c}\mathrm{O} \text { e-learning possibilita um aumento da oportunidade de melhoria da } \\
\text { educaçáo em contexto prisional. }\end{array}$ \\
\hline & $\begin{array}{l}\text { O e-learning favorece o desenvolvimento de competências de literacia digital } \\
\text { e pode oferecer um ambiente "não escolarizado", que náo esteja associado } \\
\text { com a má experiência escolar prévia de alguns formandos. }\end{array}$ \\
\hline & $\begin{array}{l}\text { Esse meio de ensino pode ser útil também para ultrapassar barreiras linguísticas, no } \\
\text { caso de reclusos estrangeiros e para a formação da equipe do estabelecimento prisional. }\end{array}$ \\
\hline \multirow{4}{*}{$\begin{array}{l}\text { Introduçáo } \\
\text { ao e-learning }\end{array}$} & $\begin{array}{l}\text { A introdução ao e-learning deve ser feita começando pelas questóes } \\
\text { pedagógicas ter em consideraçáo o ambiente da prisão, escolher os meios } \\
\text { tecnológicos apropriados; ter um plano estratégico bem definido. }\end{array}$ \\
\hline & $\begin{array}{l}\text { É importante ter em consideração o resultado de projetos transnacionais } \\
\text { para o desenvolvimento de conceitos e de produtos técnicos e pedagógicos } \\
\text { em contexto prisional. }\end{array}$ \\
\hline & $\begin{array}{c}\text { É necessário que se trabalhe em rede (entre as escolas regulares e as prisóes) } \\
\text { para que haja cooperaçáo pelo e-learning, asseguradas as questóes de } \\
\text { segurança, sendo para isso mobilizados todos os meios da organizaçáo. }\end{array}$ \\
\hline & $\begin{array}{c}\text { As pessoas, de uma forma geral, têm de ser informadas de que a introdução } \\
\text { da tecnologia é uma medida necessária para fornecer qualificaçóes atualizadas } \\
\text { e melhorar as oportunidades de reinserção social e de trabalho e, finalmente, } \\
\text { reduzir o risco e os custos de reincidência. }\end{array}$ \\
\hline \multirow{2}{*}{$\begin{array}{l}\text { Contexto de } \\
\text { aprendizagem }\end{array}$} & $\begin{array}{c}\text { Deve ser considerada a possibilidade da criação de uma Escola Virtual } \\
\text { Europeia envolvendo prisóes de vários Estados-membros. }\end{array}$ \\
\hline & $\begin{array}{l}\text { Deve ser criado um grupo de professores de estabelecimentos prisionais e de } \\
\text { especialistas em e-learning, em nível europeu, para a recolha e distribuição de } \\
\text { e-conteúdos pelos serviços correcionais. }\end{array}$ \\
\hline \multirow{2}{*}{$\begin{array}{l}\text { Utilização segura } \\
\text { da Internet }\end{array}$} & $\begin{array}{l}\text { Os sistemas de e-learning podem ser configurados de forma que apenas os } \\
\text { conteúdos apropriados possam ser acessados pelos(as) reclusos(as). }\end{array}$ \\
\hline & $\begin{array}{l}\text { Devem ser estimulados projetos-piloto que demonstrem aos gestores de } \\
\text { estabelecimentos prisionais, agentes de autoridade e professores que a Internet } \\
\text { pode ser utilizada de forma segura e de que forma isso pode ser feito. }\end{array}$ \\
\hline \multirow{4}{*}{$\begin{array}{l}\text { Incorporação do } \\
\text { e-learning }\end{array}$} & $\begin{array}{l}\text { O e-learning não pode substituir a orientaçáa dos professores no terreno. O papel } \\
\text { dos professores está se transformando, passando de instrutores a facilitadores. }\end{array}$ \\
\hline & O e-learning deve ser aplicado na modalidade blended. \\
\hline & $\begin{array}{c}\text { É necessário promover a formaçáo em e-learning junto aos funcionários dos } \\
\text { estabelecimentos prisionais. }\end{array}$ \\
\hline & É necessário mais investigaçáo acerca do impacto do e-learning em contexto prisional. \\
\hline
\end{tabular}

Fonte: LICOS (2010). 
permitissem ultrapassar as dificuldades sentidas; criação de um ambiente não escolarizado e adoção de um regime semipresencial, conforme explicitado na metodologia.

Continuando com a referência a projetos europeus em contextos prisionais, vale ressaltar que alguns países, após a participação nesses projetos com duração limitada, encontraram as suas próprias soluçôes. Exemplo disso é o projeto Elis, desenvolvido pela Alemanha e pela Áustria, o Virtual Campus, pelo Reino Unido e o Internet for inmates, pela Noruega. A experiência partilhada pelos projetos finalizados ou em curso oferece, e ofereceu-nos, no caso da formação a que se refere o estudo que aqui se apresenta, pistas para uma intervenção pensada, eficiente e efetiva.

Nesse sentido, seguindo as recomendaçóes dos projetos anteriormente referidos, é necessário conhecer as diferentes necessidades organizacionais e pedagógicas e as demandas dos ambientes de aprendizagem de diferentes EPs e ter em conta as limitaçóes dessa modalidade de ensino. Foi tendo essa recomendação por base que Lockitt (2011) analisou projetos de e-learning nas prisóes da Noruega, Suécia e Alemanha. Dessa análise, esse autor concluiu que cada país enfrenta os seus próprios problemas, em função deles, encontra diferentes soluçôes. No entanto, há dificuldades que são comuns. Lockitt (2011) identificou as que são apresentadas na Figura 1.

\section{Figura 1}

Dificuldades relativas ao e-learning no contexto prisional.

Tecnologia

- uso não efetivo

- acesso restrito

- falta de recursos com qualidade

Estabelecimento prisional

- deficiências nos processos de admissão e de formação dos formadores

- falta de agilidade na adesão da formação

- falta de liderança e de tomada de decisóes

- penas de prisão de curta duração

- falta de sensibilização dos profissionais acerca do potencial das tecnologias

\section{Formação}

- falta de continuidade dos currículos do interior e exterior da prisáo

- falta de um currículo comum com a comunidade

- oferta curricular limitada

Formandos/reclusos

- falta de motivação

- falta de formação básica

- falta de confiança/receio das tecnologias

Fonte: Lockitt (2011). 
Conscientes das limitaçóes que sistematizamos na Figura 1 e de outras limitaçóes possíveis dessa modalidade de ensino em diferentes realidades do contexto prisional, bem como da sua não neutralidade, houve na formação que estamos relatando o cuidado de conhecer os diferentes percursos em ALV das formandas/reclusas e de auscultar, a tempo, a percepção dessas participantes acerca da formação no âmbito do EPRIS, da aprendizagem em regime de e-learning e o impacto que esse teve em nível de desenvolvimento de competências de autoaprendizagem, conforme os procedimentos metodológicos que serão apresentados.

\section{Metodologia}

O estudo, de caráter interpretativo, tem orientação qualitativa, sustentado em análises qualitativas e quantitativas. Para se compreender a análise dos dados recolhidos, iniciou-se pela caracterização do contexto e das opçóes metodológicas seguidas, tecendo algumas considerações sobre a origem do estudo e como foi organizada a formação a que este artigo se refere.

\section{Origem do estudo e organização da formação}

O projeto EPRIS, que deu origem ao curso de formação a que se reporta este artigo, teve origem num projeto apresentado a um EP que pretendeu, por meio do sistema e-learning, contribuir para a reinserção social de mulheres reclusas. A opção pelo e-learning deveu-se, sobretudo, ao reconhecimento das potencialidades desse meio, enquanto dispositivo capaz de respeitar processos de diferenciaçáo pedagógica e de promover o desenvolvimento de competências necessárias aos desafios que o mundo globalizado coloca em nível de ALV. Além disso, considerou-se que, como decorrência dos processos de formação seguidos, poderiam ser desenvolvidas nas reclusas não apenas competências tecnológicas, mas também sociais.

A formação, que teve duração de 216 horas, decorreu num período de 12 meses, com início em março de 2015 e final em abril de 2016, e foi organizada em três grandes módulos: ambientação, Microsoft Office e empreendedorismo. Como já se indiciou, pretenderam-se o desenvolvimento das competências de aprendizagem on-line a distância e o estímulo ao interesse pela aprendizagem, mais do que a aprendizagem de conteúdos específicos que serviram de pontos de partida para a formação. Por isso, os conteúdos foram disponibilizados em diferentes formatos e construídos especificamente para cada módulo de modo a desenvolverem distintas competências tecnológicas e sociais. Para além disso, recorreu-se também a conteúdos selecionados e desenvolvidos pelas formandas-reclusas no âmbito das atividades propostas, os quais foram sendo utilizados ao longo do processo formativo, tais como o portfólio "ser estudante on-line". 
A plataforma de base foi a Moodle, posteriormente customizada para atender às particularidades do projeto e dar resposta às necessidades identificadas. A escolha dessa plataforma deve-se às suas caraterísticas, das quais se destacam:

- $\quad$ permitir a comunicação on-line, aspecto que foi fundamental para a garantia de um espaço de socialização on-line, de esclarecimento de dúvidas e partilha de experiências/conteúdos de aprendizagem, sendo a principal ferramenta de comunicação os fóruns;

- $\quad$ possibilitar a disponibilização de instrumentos de avaliação e consulta de opinião, o que, no caso desse curso, permitiu que em todos os módulos de formação tivssem sido disponibilizados testes, questionários e espaço de submissão de trabalhos;

- $\quad$ suportar diferentes tipos de mídia contínuos e discretos, tendo, nesse caso, sido disponibilizados conteúdos de apoio em texto, áudio e vídeo;

- registrar as entradas no ambiente de formação e as tarefas elaboradas pelos utilizadores, o que permitiu a elaboração de relatórios de atividade das formandas/reclusas que possibilitaram detectar a tempo diferentes níveis de interesse, empenho e capacidade de trabalho autônomo.

Sendo esse grupo de reclusas bastante heterogêneo no que diz respeito ao nível de escolarização e competências em TIC, optou-se pela proposta de tarefas que permitissem diferentes possibilidades de resposta e que considerassem os conhecimentos das formandas/reclusas, com um apoio presencial flexível de acordo com as necessidades de cada uma. Nesse sentido, o projeto previa sessóes presenciais ao início e final de cada módulo de formaçáo.

Os momentos presenciais constituíam-se em momentos teórico-práticos, com recursos de exposição dialogada, conversas informais sobre as dificuldades sentidas, realização de tarefas nos computadores portáteis, dinâmicas de grupo, apresentação de trabalhos, debates, role playing etc., que permitiam, por um lado, a mediação dos formadores e, por outro, a interajuda e a troca de experiências, que não era muito facilitada ao longo dos períodos on-line, em função das naturais restriçóes e logística de funcionamento de um EP.

Nos momentos on-line, as reclusas realizavam tarefas, na própria cela, em um computador pessoal portátil que lhes foi concedido para ser utilizado no decorrer da formação, sempre que desejassem ou tivessem oportunidade. A interação pela plataforma Moodle com os formadores, os recursos e as outras formandas era feita na biblioteca do EP, uma vez por semana, ou quando fosse solicitado. 


\section{Local da formação e participantes}

O EP possui aproximadamente 300 mulheres em cumprimento de pena, sendo que esse número pode variar tendo em conta a rotatividade que, segundo Silva (2013, p. 24), se deve "às constantes entradas e saídas de reclusas no EP por iniciação de cumprimento de pena, restituição à liberdade ou por transferências de outros EPs".

Depois de estabelecidos os primeiros contatos institucionais e aceitos os termos em que pretendia-se desenvolver o projeto, foram necessárias algumas reunióes preliminares com os responsáveis pelo EP e pela instituição de solidariedade social, no sentido de obtermos dados concretos sobre o tipo de público com o qual iríamos trabalhar.

A escolha das reclusas participantes foi baseada em quatro critérios fundamentais: disponibilidade e interesse em participarem no estudo; conhecimentos mínimos de informática na ótica do utilizador; escolaridade mínima correspondente ao sexto ano de escolaridade e tempo de detençáo superior ao necessário para implementar a primeira fase do projeto.

A escolha do grupo inicial de dez formandas para o estudo-piloto (número limitado pela quantidade de computadores portatéis disponíveis) ficou a cargo das técnicas da instituição de solidariedade social que desenvolvem o seu trabalho diretamente com as reclusas.

O grupo incluiu mulheres com idades entre 21 e 53 anos. O nível de escolaridade distribuiu-se equitativamente pelo terceiro ciclo do ensino básico (nono ano de escolaridade), ensino secundário (ensino médio) e ensino superior, sendo que apenas uma das formanda tem o sexto ano de escolaridade. O tempo de detençáo varia entre 15 dias e 7 anos e meio. Quanto às ocupaçóes profissionais anteriores à detenção, foram referidas: auditora $(\mathrm{n}=1)$; advogada $(\mathrm{n}=1)$; professora de desenho e de pintura $(\mathrm{n}=1)$; assistente de radiologia $(\mathrm{n}=1)$; empregada doméstica $(n=1)$; estudante $(n=1)$; desempregada $(n=1)$ e profissional de venda $(n=3)$.

\section{Instrumentos de coleta e análise dos dados}

Para alcançar os objetivos de conhecer as formandas, as suas experiências no âmbito da ALV, incluindo a perceçáo sobre as vantagens e desvantagens da formação em regime de e-learning, e as suas competências de aprendizagem, os dados foram recolhidos, presencialmente, no próprio EP onde ocorreu a formação, por meio de dois inquéritos por questionário e por um grupo focal.

Numa fase inicial, em janeiro de 2015, as dez reclusas (F1, F2, F3...F10) preencheram o primeiro questionário, disponibilizado on-line, com oito questóes abertas acerca da ALV e percepçóes iniciais e expectativas relativas à formação em e-learning. 
Em setembro de 2015, as formandas preencheram o segundo questionário, Escala de Competência de Autoaprendizagem (ECAA), de Lima Santos, Faria e Rurato (2000), adaptado para ambientes on-line por Moreira e Almeida (2011). Esse foi disponibilizado em papel numa sessão presencial, compreende três dimensões e é formado por 24 itens, avaliados por uma escala tipo Likert de cinco pontos, que varia de: discordo totalmente (1) a concordo totalmente (5). Os itens pertencentes à mesma subescala foram distribuídos de forma não consecutiva pelo questionário.

Segundo Lima Santos, Faria e Rurato (2000, p. 652), as respectivas subescalas designam-se por: "aprendizagem ativa ou aceitação da responsabilidade pessoal pela aprendizagem" (12 itens), que "avalia a perceção da capacidade para aprender em várias situações e com os outros e a aceitação da responsabilidade pessoal pelo processo de aprendizagem"; "iniciativa na aprendizagem e orientação para a experiência" (6 itens), que "avalia a orientação da aprendizagem para a experiência e para os problemas concretos, bem como a iniciativa na escolha das aprendizagens"; "autonomia na aprendizagem" (6 itens), que "avalia a autonomia nas aprendizagens em função das necessidades pessoais".

Ainda em setembro de 2015, oito formandas/reclusas participaram de um grupo focal (F1, F2, F3, F4, F5, F6, F7 e F8), técnica de entrevista em grupo que envolve a discussão estruturada a partir de temas, com o objetivo de partilhar e clarificar diferentes pontos de vista, sendo a interação moderada por um ou mais investigadores (GREENBAUM, 1998; KRUGER, 1995). Esse grupo focal, especificamente, durou cerca de uma hora, sendo moderado por três investigadores, e foi realizado presencialmente no EP onde decorreu a formação, a partir de temas preestabelecidos (satisfação com a formação, questôes técnicas e pedagógicas, impacto da formação na vivência e rotina na prisão, projeção do impacto da formação no futuro). Esses temas, apresentados na forma de perguntas, suscitaram um debate que se foi complexificando à medida que as perguntas foram passando para questóes mais gerais. As formandas/reclusas estavam sentadas em círculo e houve o cuidado de todas serem estimuladas a expressarem a sua opinião acerca dos temas abordados.

Os dados quantitivos foram tratados por meio de análise estatística simples com recurso ao programa SPSS, versão 22; os dados qualitativos foram tratados com recurso à análise de conteúdo (BOWEN, 2009). Parte dos dados recolhidos pelos dois questionários e do grupo focal serviram de base para a reflexão acerca dos resultados que passamos a apresentar.

\section{Percepções das formandas/reclusas sobre o percurso em aprendizagem ao longo da vida e a formação em e-learning}

Como sabe-se, a ALV não se restringe à educação de adultos, mas acompanha as pessoas do nascimento até o óbito. As formandas/reclusas que 
frequentaram a formação na modalidade de e-learning foram questionadas, no início da formação, acerca da participação em atividades de aprendizagem por elas já vivenciadas e dos fatores que, em sua opinião, facilitaram ou dificultaram essa participação.

Das 10 formandas, apenas 4 vivenciaram formação no âmbito de ALV e fizeram-no por meio do centro de emprego $(n=2)$, do local de trabalho $(n=1)$ e da autarquia $(n=1)$. As razóes para a procura de formação referidas foram: "ocupação do tempo" $(n=1)$; "interesse na área" $(n=1)$ e "qualificação profissional" $(\mathrm{n}=1)$. As outras seis formandas não procuraram ou não concluíram formação para além da escolaridade obrigatória ${ }^{4}$. Como razóes para essa situação, foram referidas questóes financeiras e familiares, tais como as seguintes afirmaçóes:

Tendo concluído a escolaridade obrigatória, dei preferência a ir trabalhar, pois era mais importante, para mim, conquistar a minha independência monetária (...) (Formanda 1).

Eu fui mãe muito cedo, porque sempre tive muitas restrições, e procurava um pouco de liberdade (...) (Formanda 7).

No que se refere aos fatores que dificultaram a frequência de ações de formação, as formandas reportaram a situação presente e referiram: "burocracias" ( $\mathrm{n}=1)$; "reclusão" $(\mathrm{n}=3)$; "receio de errar" $(\mathrm{n}=1)$; "falta de experiência" $(\mathrm{n}=1)$ e "falta de vontade pessoal" $(\mathrm{n}=1)$. A seguinte afirmação dá conta de alguns desses fatores:

$\mathrm{Na}$ situação em que me encontro, privada da liberdade, é tudo muito restrito e os acessos muito limitados. O pouco que se consegue ter é muito condicionado. Se estivesse noutra situação, nada me impediria, desde que tivesse vontade de fazer (Formanda 6).

Cerca de metade do total das formandas descreveu percepçóes menos agradáveis em relação à escola ou ao próprio rendimento escolar:

A escola, para mim, foi uma altura complicada (...) Sempre me senti muito só e abandonada (Formanda 7).

Sempre fui uma boa aluna, mas digamos que não gosto de usar muito do meu tempo a estudar (Formanda 4).

Não, nunca fui boa aluna, sempre fui muito preguiçosa e nunca gostei de estudar, talvez por náo saber fazê-lo, organizar-me (Formanda 6). 
Os fatores enunciados por essas mulheres reclusas coincidem com os resultados do relatório apresentado por Hawley, Murphy e Souto-Otero (2013), quando referem que as principais razóes que justificam a não participação em ALV em EP são: falta de motivação para aprender; más experiências anteriores de aprendizagem; maiores incentivos para o trabalho no interior do EP do que para o estudo; limitado número de vagas; incompatibilidade com a duração da pena e falta de diversidade da oferta formativa.

Relativamente aos fatores que facilitaram a frequência das ações de formação, os mais referidos por essas reclusas foram: "aprender mais e adquirir conhecimentos" ( $n=7)$; "investimento no futuro" ( $n=1)$; "ocupação" ( $n=1)$; "valorização pessoal" ( $n=2)$ e "relaçóes interpessoais" $(n=1)$, conforme constatado pelas seguintes afirmaçóes:

Para adquirir mais conhecimentos (Formanda 2).

Porque quero aprender mais e completar o meu futuro (Formanda 4).

Sempre que tenho oportunidade de me inscrever em açóes de formaçáo, aproveito para aumentar os meus conhecimentos, e aproveito para desenvolver as relaçóes interpessoais, e de realização pessoal (Formanda 7).

Decorrido um mês da formação, as formandas foram questionadas acerca da experiência de formaçáo vivida com recursos tecnológicos, da percepçáo acerca do conceito de e-learning e das potencialidades e limitaçóes que atribuem a esse meio de aprendizagem.

Das dez formandas, apenas duas tinham participado anteriormente em ações de formação que utilizassem recursos tecnológicos. No que diz respeito ao conceito de e-learning, as formandas referiram os seguintes fatores:

- distância: quatro formandas mencionaram que o e-learning envolve a distância, e uma delas mencionou a proximidade proporcionada: "É uma formação mais perto, em qualquer lugar" (Formanda 2);

- $\quad$ vantagens do e-learning: três formandas mencionaram vantagens do e-learning, incluindo acessibilidade; simplicidade; extensão; acesso e gestão de próprio tempo, aquisição de informações e dados úteis; inovação; indispensabilidade; uma formanda centrou a sua definição na perspectiva do aluno: "interesse de nossa parte para aproveitar e aprender" (Formanda 6).

O conceito de e-learning que orienta essas formandas enfatiza aspectos já identificados pela literatura, tais como: a tecnologia e o processo de separação 
física entre o professor e os alunos (MASIE, 2006); o processo de aprendizagem (ROSENBERG, 2001); os meios de comunicação e a relação entre fatores humanos e tecnológicos (PAULSEN, 2002).

A maioria das participantes $(\mathrm{n}=7)$ acredita que o ensino a distância é um meio credível de formação. Como vantagens, essas formandas referiram: "acesso à aprendizagem $(\mathrm{n}=2)$ "; "flexibilidade de horário" $(\mathrm{n}=2)$; "reforço da autoestima" $(\mathrm{n}=1)$; "trabalho em parceria" ( $\mathrm{n}=1)$ e "integração social e laboral" $(\mathrm{n}=1)$. Por sua vez, como desvantagens, foram referidas: "aprendizagem mais lenta, pouco contato com o professor" ( $n=1)$ e "isolamento" $(n=1)$. Sáo exemplos dessas percepçóes as seguintes afirmaçôes:

Eu acho que o ensino a distância pode ser uma mais-valia para a nossa vida, pois dá-nos oportunidade de reforçar a autoestima, a importância de trabalhar em parceria, promovendo a nossa integração na sociedade, no trabalho e mesmo no futuro de emprego no exterior (Formanda 7).

A desvantagem talvez seja alguma demora nessa aprendizagem devido ao pouco contato interpessoal, presencial entre o professor e aluno, não sei... (Formanda 1).

As vantagens enunciadas vão ao encontro dos resultados obtidos pelos projetos PIPELINE (GHK, 2010) e LICOS (LICOS, 2010). As desvantagens relativas ao e-learning em contexto prisional estão incluídas nas identificadas por Lockitt (2011) e estão, igualmente, relacionadas com as seguintes variáveis: individuais dos(as) reclusos(as) (características, experiências, atitude e motivação); institucionais (ambiente prisional, condiçóes materiais e recursos humanos); tecnológicas (hardware, software, acesso, segurança) e pedagógicas (formação, metodologia, recursos didáticos) (MONTEIRO; BARROS; LEITE, 2015).

Especificamente no processo de formação a que se reporta o presente artigo, as formandas demonstraram um grande interesse inicial em participar da formação (oito referiram estar muito motivadas e as duas restantes declaram estar motivadas). Apesar disso, à medida que a formaçáo foi decorrendo, foram surgindo dificuldades. As principais dificuldades sentidas foram: pouca disponibilidade das formandas e em conciliar o trabalho e as tarefas diárias com a elaboração das tarefas propostas semanalmente; questóes de segurança que obrigaram a ter um ponto fixo de Internet segura e que náo permitiu o acesso ao ambiente de formação no interior das celas; momentos de falta de motivação pessoal; receio em utilizar o computador e a falta de experiência com as tecnologias.

Como mencionado, pretendeu-se que essa formação em e-learning decorresse na lógica de um dispositivo de diferenciação pedagógica. Para isso, le- 
vou-se em consideração que os processos de ensino e aprendizagem têm de ser construídos em função de quem aprende, de forma a ser favorecido o desenvolvimento de competências pessoais e sociais, fundadas em interaçóes que estimulam a autoconfiança, a motivação, a autonomia e a colaboração entre pares.

\section{Percepções das formandas/reclusas sobre as competências de autoaprendizagem}

Como foi referido, foi utilizada a ECAA, de Lima Santos, Faria e Rurato (2000), adaptada para ambientes on-line por Moreira e Almeida (2011), para aferir a percepção acerca das competências de autoaprendizagem. Segundo Lima Santos, Faria e Rurato (2000, p. 652),

a competência de autoaprendizagem avaliada refere-se à aprendizagem ativa em várias situaçóes e contextos de vida, a uma atitude aberta face às oportunidades de aprendizagem e a atitudes de responsabilidade, autonomia e controlo sobre o processo de aprendizagem.

A análise dos indicadores quantitativos será complementada pelos dados obtidos por meio do grupo focal.

No que diz respeito à aprendizagem ativa, conforme a Tabela 1 , as formandas/reclusas concordaram com todas as afirmaçóes, sendo que se observou uma menor concordância com relação ao fato de estar atenta às participaçóes das outras formandas.

Com efeito, no grupo focal, as formandas referiram que têm dificuldade em encontrar-se e que náo têm o hábito de trabalhar em conjunto, conforme revela a afirmação:

Nós estamos separadas. Ela está numa ala, eu estou em outra. Então a gente, neste período de férias, nós nunca nos vimos. Se não é aqui, não nos vimos... (Formanda 2).

Ainda sobre a aprendizagem ativa, a afirmação com maior grau de concordância foi o fato de fazer perguntas, o que vai ao encontro da dependência da figura do professor, que também foi referida no grupo focal por algumas reclusas, conforme se pode exemplificar:

Eu acho que senti um bocado que precisava mais de acompanhamento... Mais tempo com o professor (Formanda 2).

A opinião das formandas/reclusas acerca da iniciativa de aprendizagem e orientação para a experiência, apresentada na Tabela 2, é, de uma forma geral, 
concordante com as afirmaçóes propostas. Destaca-se um maior grau de concordância com as afirmaçôes sobre a orientação para problemas concretos, a relação da experiência anterior na escolha de novas aprendizagens e da autorresponsabilização pelas mesmas. $\mathrm{O}$ menor grau de concordância está relacionado com a capacidade de decisão acerca dos conteúdos a serem aprendidos.

A necessidade de encontrar sentido prático para o que aprendem foi expressa por várias formandas/reclusas no grupo focal, tais como as afirmaçôes seguintes:

Eu vou ser sincera, quando um assunto não me interessa, eu não tento aprender... (Formanda 5).

Sinceramente, eu tenho ideias de abrir um restaurante em paralelo com o meu trabalho, a minha profissão, e achei giríssimo aprender a fazer as contas, as multiplicações, as percentagens (Formanda 3).

\section{Tabela 1}

Opinião das reclusas acerca do item "aprendizagem ativa".

\begin{tabular}{|c|c|c|c|}
\hline & Itens & Média* & Moda \\
\hline \multirow{12}{*}{ Aprendizagem ativa } & $\begin{array}{l}\text { Faço perguntas, nas salas de aula virtuais, } \\
\text { quando tenho dúvidas }\end{array}$ & 4,25 & 4 \\
\hline & Procuro aplicar na prática o que aprendo & 3,75 & 4 \\
\hline & $\begin{array}{c}\text { Procuro todas as informaçóes de que preciso para } \\
\text { saber mais em AOL }\end{array}$ & 3,63 & 4 \\
\hline & Sou uma pessoa mais atenta às participaçôes dos outros & 3,25 & 4 \\
\hline & $\begin{array}{l}\text { Sou capaz de aprender a ultrapassar as } \\
\text { dificuldades que me surgem em AOL }\end{array}$ & 3,88 & 4 \\
\hline & Estou sempre aprendendo com as atividades & 4,00 & 4 \\
\hline & Aprendo sempre algo de novo com as atividades & 4,13 & 4 \\
\hline & $\begin{array}{l}\text { Nas salas de aula virtuais, sou capaz de aprender } \\
\text { com pontos de vista diferentes dos meus }\end{array}$ & 4,13 & 4 \\
\hline & $\begin{array}{l}\text { Sei que sou capaz de aprender com os meus } \\
\text { erros em AOL }\end{array}$ & 4,14 & 4 \\
\hline & $\begin{array}{c}\text { Em AOL sou capaz de analisar velhos problemas } \\
\text { de novas maneiras }\end{array}$ & 3,63 & 4 \\
\hline & $\begin{array}{l}\text { Procuro aprender em todas as situaçóes } \\
\text { proporcionadas pelo professor nos Sistemas de } \\
\text { Gestão de Aprendizagem }\end{array}$ & 4,13 & 4 \\
\hline & $\begin{array}{l}\text { Gosto de aprender em AOL para melhorar } \\
\text { pessoal e academicamente }\end{array}$ & 4,13 & 4 \\
\hline
\end{tabular}

${ }^{*} 1=$ discordo totalmente; $5=$ concordo totalmente $(n=8)$; AOL: aprendizagem em ambientes on-line. 
Relativamente à autonomia na aprendizagem, a afirmação com menor grau de concordância está relacionada com considerarem saber mais do que os outros sobre o que precisam de aprender. Por outro lado, a afirmação com maior grau de concordância diz respeito à percepção de que a capacidade de aprender por si próprias está mudando, conforme excertos organizados na Tabela 3.

Essa percepção foi, de igual forma, referida por várias reclusas/formandas no grupo focal, em que muitas expressaram que a formação tem lhes devolvido confiança na própria capacidade de aprender. São disso exemplo as afirmaçóes seguintes:

Eu ganhei um bocadinho mais o gosto de estudar, se calhar quem sabe poderei entrar para a faculdade... Tentar, não é? (...) Eu pensava que, se calhar, era mais burra do que sou, por exemplo (Formanda 6).

Eu falo por mim, há tanto tempo tive parada em relação a qualquer coisa como estudar..., isto veio mudar a minha perspectiva, até pensar que era possível (Formanda 2).

Mas tenho atingido sempre todos os objetivos propostos, é verdade que às vezes, se calhar, demoro mais tempo a fazer os trabalhos pedidos, mas como sou muito persistente e acho que tenho que saber e tenho que aprender, tenho conseguido. Realmente, se calhar, levo mesmo sempre mais tempo do que cada uma delas, mas pelo menos consigo fazer... (Formanda 3).

\section{Tabela 2}

Opinião das reclusas acerca do item "iniciativa de aprendizagem".

\begin{tabular}{l|c|c|c}
\hline & Itens & Média* & Moda \\
\hline \multirow{4}{*}{$\begin{array}{l}\text { Iniciativa de } \\
\text { aprendizagem }\end{array}$} & $\begin{array}{c}\text { Oriento as minhas AOL em função de } \\
\text { problemas concretos }\end{array}$ & 4,13 & 4 \\
\cline { 2 - 4 } & $\begin{array}{c}\text { Tenho em conta a minha experiência quando } \\
\text { escolho novas aprendizagens }\end{array}$ & 4,13 & 4 \\
\cline { 2 - 4 } & $\begin{array}{c}\text { Sou capaz de gerir cada vez melhor as minhas } \\
\text { aprendizagens em AOL }\end{array}$ & 3,75 & 4 \\
\cline { 2 - 4 } & $\begin{array}{c}\text { Em ambiente on-line, dirijo as minhas atençóes } \\
\text { para o que é útil }\end{array}$ & 4,00 & 4 \\
\cline { 2 - 4 } & Sou capaz de decidir o que devo aprender em AOL & 3,63 & 4 \\
\cline { 2 - 4 } & $\begin{array}{c}\text { Em AOL, sou responsável pelas minhas } \\
\text { aprendizagens }\end{array}$ & 4,13 & 4 \\
\hline
\end{tabular}

${ }^{*} 1=$ discordo totalmente; $5=$ concordo totalmente $(n=8) ; A O L$ : aprendizagem em ambientes on-line. 
Tabela 3

Opinião das reclusas acerca do item "autonomia na aprendizagem".

\begin{tabular}{|c|c|c|c|}
\hline & Itens & Média* $^{*}$ & Moda \\
\hline \multirow{6}{*}{$\begin{array}{l}\text { Autonomia na } \\
\text { aprendizagem }\end{array}$} & $\begin{array}{l}\text { Sou uma pessoa mais ativa nas atividades quando } \\
\text { sei as razóes do que vou aprender }\end{array}$ & 3,5 & 4 \\
\hline & Tenho vontade de aprender por mim mesmo em AOL & 4,00 & 4 \\
\hline & $\begin{array}{c}\text { A minha capacidade de aprender por mim mesmo } \\
\text { está mudando }\end{array}$ & 4,25 & 4 \\
\hline & $\begin{array}{c}\text { Em AOL, sei melhor do que as outras pessoas sobre } \\
\text { o que preciso aprender }\end{array}$ & 3,25 & 4 \\
\hline & $\begin{array}{c}\text { Em AOL, aprendo bem aquilo que me permite } \\
\text { enfrentar situaçôes reais }\end{array}$ & 3,88 & 4 \\
\hline & $\begin{array}{l}\text { Em AOL, aprendo melhor aquilo que preciso para } \\
\text { executar bem as tarefas }\end{array}$ & 4,13 & 4 \\
\hline
\end{tabular}

${ }^{*} 1=$ discordo totalmente; $5=$ concordo totalmente $(n=8) ; A O L$ : aprendizagem em ambientes on-line.

\section{Considerações Finais}

O reconhecimento da importância das TIC na educação e formação de adultos, especialmente para expandir as oportunidades de ALV, tem sido a base do desenvolvimento de projetos europeus que têm o objetivo de maximizar o potencial das TIC como instrumento de apoio à aprendizagem e ao ensino a distância ou para promover competências em TIC e aumentar a literacia digital entre os(as) reclusos(as) (HAWLEY; MURPHY; SOUTO-OTERO, 2012).

Os resultados de projetos europeus fornecem orientaçóes e recomendaçóes para o trabalho a ser desenvolvido em outros projetos, adequados a distintos contextos. Permitem também refletir sobre as potencialidades que oferecem e as soluçóes encontradas para as eventuais dificuldades. As potencialidades dizem respeito, em geral, à flexibilidade do tempo e do espaço, à diversificação dos meios e da oferta formativa, à possibilidade de continuidade da formação e ao aumento da motivação dos(as) formandos(as), principalmente para aqueles(as) com más experiências relativamente ao contexto formal de educação. As soluçóes que têm sido encontradas, tal como referido neste artigo a propósito do contexto prisional, envolvem a parceria entre os responsáveis pela formação, a gestão do EP e o pessoal responsável pela segurança e pelo departamento de formação. Envolvem, ainda, a participação efetiva de quem está em formação em todas as fases do projeto e a construção partilhada de conhecimentos por parte de todos os intervenientes.

$\mathrm{Na}$ formação a que o estudo aqui apresentado se refere e de acordo com os dados recolhidos, é possível concluir que o e-learning, em ambiente prisional, adquire potencialidades em termos de formação e no que concerne à promoçáo da motivaçáo para o envolvimento na aprendizagem. Possibilita ainda saber que esses efeitos favorecem mudanças relativas à perceção das competências de aprendizagem das formandas em situação de reclusão. 
Observou-se, no discurso das reclusas, fragilidades quanto ao conceito que têm de si próprias, enquanto aprendentes e, sobretudo, descontinuidades em relação à disposição para o envolvimento nas atividades de aprendizagem. Os dados permitiram também concluir que a possibilidade efetiva de empoderamento que ocorreu com essas formandas está relacionada com o recurso a processos de corresponsabilização ao longo de todas as etapas do processo formativo.

O fato dessa formação ter constituído uma oportunidade para algumas das reclusas de conviverem com as TIC favoreceu uma socialização necessária à vivência numa sociedade tecnológica. Apesar disso, esses dados mostram também a necessidade de se ter em conta o contexto em que decorre a aprendizagem e as especificidades que o atravessam. A existência de limitaçóes à criação de ambientes seguros e de acesso aos recursos tecnológicos constituiu um obstáculo que não pode ser ignorado e que exige uma constante negociação. A essa dificuldade há que acrescentar ainda as que decorrem do desentusiasmo que a vida em reclusão tantas vezes oferece.

Em síntese, a análise dos dados permite concluir que, apesar do histórico de pouca participação em atividades de ALV e de algumas dificuldades e resistências relacionadas com más experiências de formação escolarizada, essas formandas, na situação de reclusão, demonstraram que a experiência de formação em e-learning devidamente apoiada lhes devolveu a confiança de que ainda têm capacidade para aprender, constituindo também uma mais-valia pessoal para o futuro profissional e para a inserção no mercado de trabalho.

\section{Notas}

1. Segundo dados do estudo Survey on Prison Education and Training in Europe - Final Report (HAWLEY; MURPHY; SOUTO-OTERO, 2012).

2. Tradução das autoras. Original: "Open and flexible learning environments are characterized by: "reflect the multiple and diverse cultural realities of both minority and mainstream societies; include multiple cultural ways of knowing, interacting, learning and teaching; promote acceptance and equity of a variety of learning outcomes" (NGEOW; KONG, 2002: p. 2).

3. Atualmente, a UE incorporou todos os subprogramas no ERASMUS + (COMISSÃO EUROPEIA, 2014).

4. Em 2009, a escolaridade obrigatória, em Portugal, passou dos 9 (terceiro ciclo do ensino básico) para 12 (ensino secundário) ou 18 anos.

\section{Referências}

APOSTOPOULOU, G. et al. E-learning para a inclusão social. Barcelona: Délégation aux usages de l'internet, 2004. Disponível em: <http://charte.velay.greta.fr/pdf/charter Elearning para inclusao social.pdf $>$. Acesso em: 6 jul. 2011. 
BARROS, R.; MONTEIRO, A. E-learning for lifelong learning offemale inmates: the epris project. EDULEARN15 Proceedings. Barcelona: IATED, 2015. p. 7056-7063.

BOWEN, G.A. Document analysis as a qualitative research method. Qualitative Research Journal, v. 9, n. 2, p. 27-40, 2009.

COMISSÃO DAS COMUNIDADES EUROPEIAS. eEurope 2002: uma sociedade de informação para todos. Bruxelas, 2000. Disponível em: <http://eur-lex.europa.eu/legalcontent/pt/TXT/PDF/?uri=CELEX:52000DC0330\&rid=13>. Acesso em: 10 jan. 2015.

COMISSÃO EUROPEIA. Communication from the commission Europe 2020: A strategy for smart, sustainable and inclusive growth. Bruxelas, 2010. Disponível em: <http://eur-lex.europa. eu/LexUriServ/LexUriServ.do?uri=COM:2010:2020:FIN:pt:PDF>. Acesso em: 20 jun. 2015.

. Erasmus +. 2014. Disponível em: <http://ec.europa.eu/programmes/erasmusplus/index pt.htm>. Acesso em: 12 jan. 2015.

CORTESÃO, L. Professor: produtor e/ou tradutor de conhecimentos? Trabalhando no contexto do arco-íris sociocultural da sala de aula. Educação \& Realidade, v. 37, n. 3, p. 719-735, 2012.

CORTESÃO, L.; STOER, S.R. Acerca do trabalho do professor: da tradução à produção do conhecimento no processo educativo. Revista Brasileira de Educação, v. 11, p. 33-45, 1999.

GHK. Grundtvig and Leonardo da Vinci catalogue of projects on prison education \& training. Budapest: Lifelong Learing Programme Grundtvig, 2010. Disponível em: <http://www.exocop.eu/sixcms/media.php/13/Documents-Doc4-EACProjectsAnalysisUpdated2012 web.pdf >. Acesso em: 2 jan. 2015.

GREENBAUM, T.L. The handbook offocus group research. London: Sage Publications, 1998.

GUIMARÃES, P.; BARROS, R. A nova política pública de educação e formação de adultos em Portugal. Os educadores de adultos numa encruzilhada? Educação \& Sociedade, v. 36, n. 131 , p. 391-406, 2015.

HAWLEY, J.; MURPHY, I.; SOUTO-OTERO, M. Prison education and training in Europe: current state-of-play and challenges. Birmingham: GHK, 2013. Disponível em: <http:// ec.europa.eu/education/library/study/2013/prison en.pdf $>$. Acesso em: 5 jan. 2015.

. Survey on prison education and training in Europe: Final Report. Birmingham: GHK, 2012. Disponível em: <http://www.epeamalta.org/uploads/3/0/6/4/3064611/ survey on prison education and training.pdf $>$. Acesso em: 12 dez. 2014.

KRUGER, R.A. Focus groups: a practical guide for applied research. Thousand Oaks: Sage Publications, 1995.

LEARNING INFRASTRUCTURE FOR CORRECTIONAL SERVICES (LICOS). E-learning in prison education in Europe: recommendations for european policy makers. 2010. Disponível em: <http://www.adam-europe.eu/prj/3840/prj/33-lcrecommendations-elearning-prison-10.pdf>. Acesso em: 1 jun. 2015.

LIMA SANTOS, N.L.; FARIA, L.; RURATO, P. Educação e aprendizagem de adultos: avaliaçáo do autoconceito de competência cognitiva e da autoaprendizagem. Revista Galego-Portuguesa de Psicoloxía e Educación, v. 6, n. 4, p. 649-656, 2000. 
LOCKITT, W.G. Technology in prisons. Winston Churchill 2010 Travelling Fellowship. 2011. Disponível em: <http://www.wcmt.org.uk/sites/default/files/migratedreports/797 1.pdf $>$. Acesso em: 1 dez. 2014.

MASIE, E. The blended learning imperative. In: BONK, C.; GRAHAM, C. (Eds.). The handbook of blended learning: global perspectives, local designs. San Francisco: Pfeifer, 2006. p. 22-26.

MONTEIRO, A.; BARROS, R.; LEITE, C. Lifelong learning through e-learning in european prisons: rethinking digital and social inclusion. INTED2015 Proceedings. Madrid: IATED, 2015. p. 1038-1046.

MOREIRA, J.M.; ALMEIDA, C. Self-concept of competence of higher education students learning in virtual environments. In: MUENDEZ-VILLAS, A. (Ed.). Education in a technological world: communicating current and emerging research and technological efforts. Badajoz: Formatex, 2011. p. 399-405.

NGEOW, K.; KONG, K.Y.S. Designing culturally sensitive learning environments. Auckland: ASCILITE, 2002. Disponível em: <http://www.ascilite.org/conferences/ auckland02/proceedings/papers/055.pdf>. Acesso em: 7 nov. 2014.

ORGANIZAÇÃO DAS NAÇÓESS UNIDAS PARA A EDUCAÇÃO, A CIÊNCIA E A CULTURA (UNESCO). Declaração REA de Paris em 2012. 2012. Disponível em: < http:// www.unesco.org/new/fileadmin/MULTIMEDIA/HQ/CI/CI/pdf/Events/Portuguese Paris_OER_Declaration.pdf $>$. Acesso em: 14 mai. 2015.

PAULSEN, M.F. Sistemas de educação online: discussão e definição de termos. In: KEEGAN, D. et al. (Eds.). E-Learning: o papel dos sistemas de gestão da aprendizagem na Europa. Lisboa: Inofor, 2002. p. 19-31.

PORTUGAL. Decreto-lei n. 42, de 22 de fevereiro de 2005. Diário da República, I, série A, n. 37, p. 1494-9, 22 fev. 2005. Disponível em: <http://www.dges.mctes.pt/NR/rdonlyres/AE6762DF1DBF-40C0-B194-E3FAA9516D79/1773/DL42 2005.pdf s. Acesso em: 1 mar. 2015.

RANGEL, H. Estratégias sociais e educação prisional na Europa: visão de conjunto e reflexôes. Revista Brasileira de Educação, v. 12, n. 34, p. 81-93, jan./abr. 2007.

ROSENBERG, M.J. E-learning: strategies for delivering knowledge in the digital age. New York: McGraw-Hill, 2001.

SILVA, J. A influência da experiência de reclusão na formação das perspetivas de (re) integração social de mulheres em cumprimento de pena. Dissertaçáo (Mestrado Integrado de Psicologia) Faculdade de Psicologia e de Ciências da Educação, Universidade do Porto, Porto, 2013.

VALLE, L.; BOHADANA, E.D.B. Interação e interatividade: por uma reantropolização da EaD online. Educação \& Sociedade, v. 33, n. 121, p. 973-984, 2012.

Recebido em 16 de novembro de 2015.

Aprovado em 22 de agosto de 2016.

(C) 2018 Centro de Estudos Educação e Sociedade - CEDES Este é um artigo de acesso aberto distribuído nos termos de licença Creative Commons. 